Check for updates

Cite this: RSC Adv., 2019, 9, 16044

Received 9th March 2019

Accepted 3rd May 2019

DOI: $10.1039 / c 9 r a 01801 \mathrm{~h}$

rsc.li/rsc-advances

\section{Changes of flooding reagents' properties under simulated high temperature/pressure conditions in oil reservoirs and their impact on emulsion stability}

\author{
Dong Chen, iD abc Yingxin Gao, ${ }^{\text {ab }}$ Dejun Sun, ${ }^{d}$ Yujiang Li, (iD e Feng Li ${ }^{\mathrm{ab}}$ \\ and Min Yang*ab
}

It is of great significance to know the fate of the polymers and surfactants used for enhanced oil recovery (EOR) in oil reservoirs at a relatively high temperature/pressure. In this paper, the changes of the properties of a polymer (partially hydrolyzed polyacrylamide, HPAM) and a surfactant (petroleum sulfonate, PS) were investigated under simulated oil reservoir conditions (a temperature of 45,60 or $75{ }^{\circ} \mathrm{C}$ and a pressure of 10,15 or $20 \mathrm{MPa}$ ). The impacts of the property changes to emulsion stability were also highlighted. The results showed that the hydrolysis degree of HPAM increased from $24.3 \%$ to $28.9 \%, 29.7 \%$ and $35.4 \%$, whereas the molecular weight $\left(M_{\mathrm{w}}\right)$ decreased from $7.60 \times 10^{6} \mathrm{~g} \mathrm{~mol}^{-1}$ to $5.43 \times 10^{6} \mathrm{~g} \mathrm{~mol}^{-1}, 4.49 \times$ $10^{6} \mathrm{~g} \mathrm{~mol}^{-1}$ and $2.87 \times 10^{6} \mathrm{~g} \mathrm{~mol}^{-1}$ as a function of raising the temperature to 45,60 and $75{ }^{\circ} \mathrm{C}$ with $20 \mathrm{MPa}$, respectively, for a duration of one week. However, the increased pressure showed obvious prevention effects on the degradation of HPAM $M_{\mathrm{w}}$ in the investigated pressure range of 10-20 MPa. There were no changes in the oil-water interfacial tension for PS solutions after high temperature/ pressure treatment. The stabilization ability of HPAM to the emulsion decreased markedly after treatment because of the decreased viscosity attributed to the reduction of molecular weight, while that of PS did not change. It is reasonable to speculate that the influence of back produced HPAM to the stability of EOR produced water will be quite different in different oil reservoirs because of the differences in reservoir temperature, pressure and retention time, and therefore different strategies should be considered in treating the produced water from EOR.

\section{Introduction}

Recently, enhanced oil recovery (EOR) using polymers (in most cases, partially hydrolyzed polyacrylamide, HPAM) and in some cases together with surfactants (such as petroleum sulfonate, PS) has been increasingly employed to increase oil recovery. ${ }^{1-5}$ The use of polymers is supposed to increase the sweep efficiency and the use of surfactants to improve the oil displacing efficiency. ${ }^{6-10}$ These polymers and surfactants remain in produced water (PW) after being back-produced from oil reservoirs. ${ }^{11,12}$ It has been reported that the presence of residual polymers and surfactants in PW could greatly enhance the stability of an oil/ water emulsion, making it more difficult to be treated by conventional PW treatment methods., ${ }^{6,13}$ A study in Oman

\footnotetext{
${ }^{a}$ State Key Laboratory of Environmental Aquatic Chemistry, Research Center for Eco-Environmental Sciences, Chinese Academy of Sciences, Beijing, 100085, China. E-mail: yangmin@rcees.ac.cn

${ }^{b}$ University of the Chinese Academy of Sciences, Beijing, 100019, China

${ }^{c}$ Sino-Danish Center for Education and Research, Beijing, 100190, China

${ }^{d}$ Key Laboratory of Colloid \& Interface Science of Education Ministry, Shandong University, Jinan, China

${ }^{e}$ School of Environmental Science \& Engineering, Shandong University, Jinan, China
}

reported that the emulsion formed in a polymer bearing PW was more stable than the polymer free one due to the increased viscosity. ${ }^{14}$ A study in China reported that the oil content of PW containing $40 \mathrm{mg} \mathrm{L}^{-1}$ HPAM was 6 times that of a polymer free one. ${ }^{15}$ Simulation experiments using a surfactant (alkylbenzene sulphonate as the major component) showed that the residual oil in PW increases as a function of surfactant concentration. ${ }^{\mathbf{1 6}}$ The decreased oil-water interfacial tension in the presence of surfactants and the increased viscosity in the presence of polymers have been speculated to be responsible for the increased emulsion stability of PW. ${ }^{\mathbf{1 4 - 1 6}}$

On the other hand, these flooding reagents stay in the oil reservoirs for a long time before being back produced to the surface. It is known that the temperature could be as high as $80^{\circ} \mathrm{C}$, or even higher, and the pressure would be as high as over $20 \mathrm{MPa}$ in the reservoirs with a depth of over $2000 \mathrm{~m} .{ }^{17-21}$ It has been reported that polymers such as HPAM would experience appreciable degradation under a temperature of $75{ }^{\circ} \mathrm{C} .{ }^{22}$ Thus it is important to know the fate of flooding reagents (polymers and surfactants) in the oil reservoirs, and how such changes of the EOR reagents will affect the stability of the PW emulsion.

In this paper, the influences of high temperature $(45,60$ and $75{ }^{\circ} \mathrm{C}$, respectively) and high pressure (10, 15 and $20 \mathrm{MPa}$, 
respectively) on the properties of HPAM and PS were investigated using specially designed stainless reactors. The changes in the molecular weight of HPAM and the interfacial properties of PS were followed, and the consequential influence on the oil/ water emulsion stability was further explored. The results of this study would provide useful information to better understand the stabilization mechanism of EOR PW, and to develop more efficient PW treatment technologies.

\section{Experiments}

\subsection{Materials and preparation of stock solutions}

Laboratory grade chemicals including sodium chloride, potassium chloride, calcium chloride, magnesium chloride, sodium sulfate and sodium hydrogen carbonate of analytical degree were purchased from Sinopharm Chemical Reagent Beijing Co., Ltd (Beijing, China). Partially hydrolyzed polyacrylamide (HPAM) and petroleum sulfonate (PS) which are used as the EOR reagents in oilfields were purchased from Beijing Hengju, and Daqing Oilfield Companies, respectively. Crude oil from Jidong Oilfield (Hebei, China) was employed in the oil-water interfacial tension measurements and simulated emulsion experiments. A stock solution of HPAM $\left(200 \mathrm{mg} \mathrm{L}^{-1}\right)$ was prepared by adding HPAM slowly to the vertex of distilled water established by magnetic stirring (500 RPM, 5 minutes), and then stirred for 5 days at 100 RPM. The stock solution of petroleum sulfonate $\left(2000 \mathrm{mg} \mathrm{L}^{-1}\right)$ was also prepared using distilled water. The brine used to prepare a simulated emulsion contained $0.473 \mathrm{~g} \mathrm{~L}^{-1} \mathrm{MgSO}_{4} \cdot 7 \mathrm{H}_{2} \mathrm{O}, 6.064 \mathrm{~g} \mathrm{~L}^{-1} \mathrm{NaHCO}_{3}$, $0.512 \mathrm{~g} \mathrm{~L}^{-1} \mathrm{CaCl}_{2}, 8.740 \mathrm{~g} \mathrm{~L}^{-1} \mathrm{KCl}$, and $3.868 \mathrm{~g} \mathrm{~L}^{-1} \mathrm{Na}_{2} \mathrm{SO}_{4}$ (its salinity degree was $19414 \mathrm{mg} \mathrm{L}^{-1}$ ).

\subsection{Reactors, treatment and the stability tests of simulated emulsion}

The designed reactors were made of stainless steel, and Teflon was used as the inner plastic container with an effective volume of $220 \mathrm{~mL}$. Each reactor was equipped with a pressure meter connected with a titanium alloy tube. The reactors could tolerate a pressure as high as $50 \mathrm{MPa}$ and a temperature as high as $100{ }^{\circ} \mathrm{C}$. Three temperatures $\left(45,60\right.$ and $75{ }^{\circ} \mathrm{C}$, respectively) under three pressure conditions $(10,15$ and $20 \mathrm{MPa}$, respectively) were applied for the treatment. The temperature was adjusted using a water bath, and the pressure in reactors was adjusted using a mechanical pressurizing pump. The reactors were kept at given temperature/pressure conditions for 1 week before analysis and further simulation experiments. All the experiments were performed in triplicate, and solutions without treatment set at room conditions for 1 week were used as control. Over the whole experimental period, there was no precipitation in the solutions, and the $\mathrm{pH}$ of the polymer solutions was between 6.0 and 6.5 .

A simulated emulsion containing PS was prepared by mixing $30 \mathrm{~mL}$ treated PS solution (2000 $\mathrm{mg} \mathrm{L}^{-1}$ ), $30 \mathrm{~mL}$ brine, $60 \mathrm{~mL}$ distilled water and $0.60 \mathrm{~g}$ crude oil in a homogenizer (Blender 8010ES, Warring Laboratory Science, USA) for 3 minutes. An emulsion containing HPAM was also prepared by mixing $60 \mathrm{~mL}$ treated HPAM solution $\left(200 \mathrm{mg} \mathrm{L}^{-1}\right), 30 \mathrm{~mL}$ PS stock solution $\left(2000 \mathrm{mg} \mathrm{L}^{-1}\right), 30 \mathrm{~mL}$ brine and $0.60 \mathrm{~g}$ crude oil in the homogenizer for 3 minutes. Before homogenization of all the solutions, crude oil and the homogenizer were respectively preheated at $40{ }^{\circ} \mathrm{C}$ for $1 \mathrm{~h}$. The acquired simulated emulsion with the oil concentration of $5000 \mathrm{mg} \mathrm{L}^{-1}$ and the salinity of $4853.5 \mathrm{mg} \mathrm{L}^{-1}$ was then kept at $45^{\circ} \mathrm{C}$ for $24 \mathrm{~h}$, and after that the remaining oil concentration was measured. Each test was repeated three times, and the average value was used.

\subsection{Measurements}

The viscosity of the HPAM solution was measured using a viscometer (Brookfield DV3T, USA) with an ultra-low adapter (0) at $25{ }^{\circ} \mathrm{C}$. The hydrolysis degree of HPAM was determined by titration methods. The oil-water interfacial tension was measured on TX-500C (CNG USA Co., USA) at $40{ }^{\circ} \mathrm{C}$. The oil content was determined on an ultraviolet spectrophotometer (PERSEE, Beijing, China) at $430 \mathrm{~nm}$ after extraction using petroleum ether $(\mathrm{pH}<2) .{ }^{15}$

The molecular weight $\left(M_{\mathrm{w}}\right)$ of HPAM was determined on the ALV/CGS-3 Compact Goniometer System (ALV, Germany) equipped with a multitau digital time correlator (ALV 5000) and a cylindrical $22 \mathrm{~mW}$ JDS-Uniphase He-Ne laser $\left(\lambda_{0}=632.8 \mathrm{~nm}\right)$. Scattered light intensity was collected for a duration of $5 \mathrm{~min} 3$ times (under $d_{\text {Rate }}<3 \%$ ) for each scattering angle $(\theta)$ from 30 to $110^{\circ}$ with an interval of $10^{\circ}$ at different HPAM concentrations. The temperature was controlled by a programmable circulation bath at $25.00 \pm 0.01^{\circ} \mathrm{C}$. Zimm formulation as follows was used to determine the molecular weight via extrapolation of polymer concentration $(c)$ and scattering angle $(\theta)$ to zero. ${ }^{23,24}$

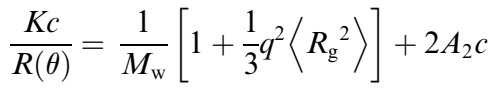

where $K=4 \pi^{2} n^{2}(\mathrm{~d} n / \mathrm{d} c)^{2} /\left(N_{\mathrm{A}} \lambda_{0}{ }^{4}\right), q=\left(4 \pi n / \lambda_{0}\right) \sin (\theta / 2)$ is the magnitude of the scattering vector and $A_{2}$ is the second viral coefficient, with $N_{\mathrm{A}}, R(\theta), n, c, \lambda_{0}, M_{\mathrm{w}}, R_{\mathrm{g}}$ and $\theta$ being Avogadro's constant, the Rayleigh ratio, the solvent refractive index, the solute concentration $\left(\mathrm{g} \mathrm{mL}^{-1}\right)$, the light wavelength in a vacuum, the weight averaged molecular weight, the $z$-averaged squared radius of gyration and the scattering angle, respectively. The $\mathrm{d} n / \mathrm{d} c$ of HPAM in $1 \mathrm{moL} \mathrm{L}^{-1} \mathrm{NaCl}$ solution is 0.1553 $\pm 0.0049 \mathrm{~mL} \mathrm{~g}^{-1}$ measured by differential refractometers (Wyatt, America), which was consistent with the reported value with the molecular weight range of $1.22 \times 10^{6}$ to $12.6 \times 10^{6} \mathrm{~g}$ $\mathrm{mol}^{-1} \cdot{ }^{25}$

\section{Results and discussion}

\subsection{The molecular weight $\left(M_{\mathrm{w}}\right)$ changes of HPAM}

The HPAM $M_{\mathrm{w}}$ was measured using static light scattering (SLS) to explore the effects of simulated temperature/pressure conditions on the polymer chains degradation. As shown in Fig. 1(A), the Zimm formulation is very good at evaluation of the weight averaged molecular weight for HPAM, and the $M_{\mathrm{w}}$ of control HPAM was $7.60 \times 10^{6} \mathrm{~g} \mathrm{~mol}^{-1}$. After one week of treatment at temperatures of 45,60 and $75{ }^{\circ} \mathrm{C}$ with $20 \mathrm{MPa}$, the 

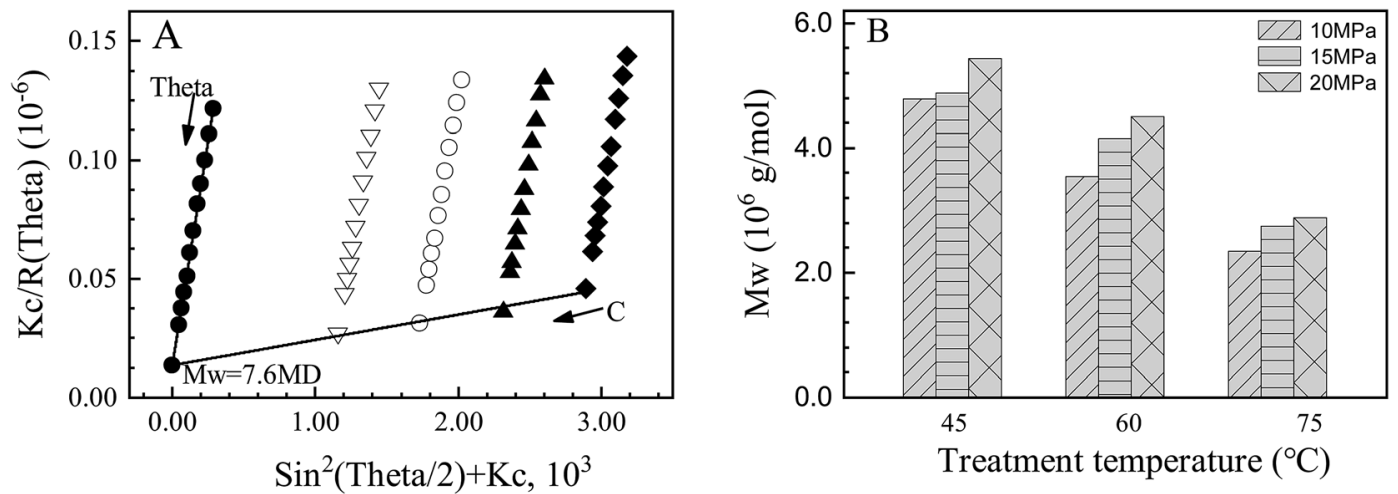

Fig. 1 The typical Zimm-plot of static light scattering data for HPAM in $1 \mathrm{moL} \mathrm{L}^{-1} \mathrm{NaCl}$ solution at concentrations of $0.04,0.08,0.12,0.20 \mathrm{~g} \mathrm{~L}-1$ under $25.00^{\circ} \mathrm{C}$ and molecular weight variations of HPAM after treatment of high temperature/pressure. (A) Represents the $M_{w}$ of the control HPAM and (B) represents the $M_{w}$ of the treated one.

$M_{\mathrm{w}}$ of the HPAM decreased greatly to $5.43 \times 10^{6}, 4.49 \times 10^{6}$ and $2.87 \times 10^{6} \mathrm{~g} \mathrm{~mol}^{-1}$, respectively. However, the pressure has shown obvious resistance effects on the degradation of the HPAM $M_{\mathrm{w}}$, as the pressure increasing the $M_{\mathrm{w}}$ increased for the investigated pressure range. It was reported that the polymer degradation originated from the radical reactions caused by the residual initiators (used for the copolymerization of the monomers) in the polymer products, which usually include four steps, i.e., chain initiation, propagation, transfer and termination. ${ }^{22}$ Higher pressure may have depressed one of the four steps. However, more efforts are required to elucidate the degradation mechanisms. The result of this study was in accordance with a previous study showing that polyacrylamide with an $M_{\mathrm{w}}$ of $2.4 \times 10^{6}$ and $4.8 \times 10^{5} \mathrm{~g} \mathrm{~mol}^{-1}$ degraded markedly after thermal treatment at $75{ }^{\circ} \mathrm{C}$ for 5 days according to the determination of GPC. ${ }^{26}$ However, in another study using the Mark-Houwink equation method, it was found that the $M_{\mathrm{w}}$ of HPAM (hydrolysis degree: $28 \%$ ) decreased from $1.6 \times 10^{6}$ to $1.35 \times 10^{6}, 0.48 \times 10^{6}, 0.87 \times 10^{6}, 1.14 \times 10^{6}$ and $1.26 \times 10^{6} \mathrm{~g}$ $\mathrm{mol}^{-1}$ even after being treated at 26, 40, 60, 70 and $80{ }^{\circ} \mathrm{C}$ for 4 hours. ${ }^{27}$ It seemed that the SLS and GPC methods exhibited similar results, but the Mark-Houwink equation method gave some different results. The latter one gives the measurement results based on the intrinsic viscosity of polymer solutions, which might be affected by the change of the hydrolysis degree. ${ }^{27,28}$

\subsection{The change of the HPAM hydrolysis degree and solution viscosity}

The measured value of the HPAM hydrolysis degree was $24.3 \%$, which was in accordance with the value provided by the manufacture (25\%). As shown in Fig. 2(A), the hydrolysis degree of HPAM increased to $28.9,29.7$ and $35.4 \%$ with the increase of temperature to 45,60 and $75^{\circ} \mathrm{C}$, respectively, while the increase of pressure did not result in perceptible changes. A previous kinetics study on the hydrolysis of polyacrylamide $\left(M_{\mathrm{w}}\right.$ : $6 \times$ $10^{6} \mathrm{~g} \mathrm{~mol}^{-1}$, hydrolysis degree: $0-37 \%$ ) found that it was closely related to the initial hydrolysis degree and $\mathrm{pH}$ condition, after a treatment of 10 days at $80{ }^{\circ} \mathrm{C}$ under $\mathrm{pH} 6.5$, it increased by
$13 \%$ with the initial value less than $17 \%$ and increased $8 \%$ when the initial hydrolysis degree was in the range of $17-27 \% .{ }^{29}$ Here, with the similar original hydrolysis degree, $\mathrm{pH}$ condition and molecular weight level, the hydrolysis degree increased about $11 \%$ after a treatment of 7 days at $75^{\circ} \mathrm{C}$, which was consistent with the literature.

The viscosity of the HPAM solution is a key factor for the oil recovery process and the stability of the PW emulsion formed during this process. As shown in Fig. 2(B), the viscosity of the control HPAM solution was $8.39 \mathrm{cP}$, which was reduced to 8.06, 8.01 and $7.28 \mathrm{cP}$ with the increase of the treatment temperature to 45,60 and $75^{\circ} \mathrm{C}$, respectively. The viscosity of the solution is mainly determined by the molecular weight and the hydrolysis degree of polymers. The viscosity of the polymer solutions was found to increase linearly with the molecular weight of the added polymer. ${ }^{30,31}$ For the same molecular weight, the viscosity of the polymer increases firstly with the increase of the hydrolysis degree, and then decreases due to the weaker electrostatic effects or the condensation of the counter-ion around the carboxylate groups on the polymer chain..$^{32,33}$ So the decrease of the HPAM solution viscosity was mainly attributed to the degradation of the molecular weight in this study.

\subsection{The impact of increased temperature and pressure on interfacial tensions of PS solutions}

The oil-water interfacial tensions for the solutions containing a concentration of $150 \mathrm{mg} \mathrm{\textrm {L } ^ { - 1 }}$ control or treated PS were measured with a salinity of $4853.5 \mathrm{mg} \mathrm{L} \mathrm{L}^{-1}$ at $40{ }^{\circ} \mathrm{C}$ for 60 minutes, as shown in Fig. 3. There was no obvious difference between the control and the treated solutions, suggesting that treatment under a relatively high temperature/pressure would not affect the oil-water interfacial properties of the surfactant.

\subsection{The impact of increased temperature on the oil-water emulsion stabilization ability of HPAM/PS}

The remaining oil content was used to indicate the oil-water emulsion stability. As shown in Fig. 4(A), the oil-water emulsion stabilization ability of PS after treatment at $45-75{ }^{\circ} \mathrm{C}$ did not decrease. It is known that the contribution of surfactants to the 

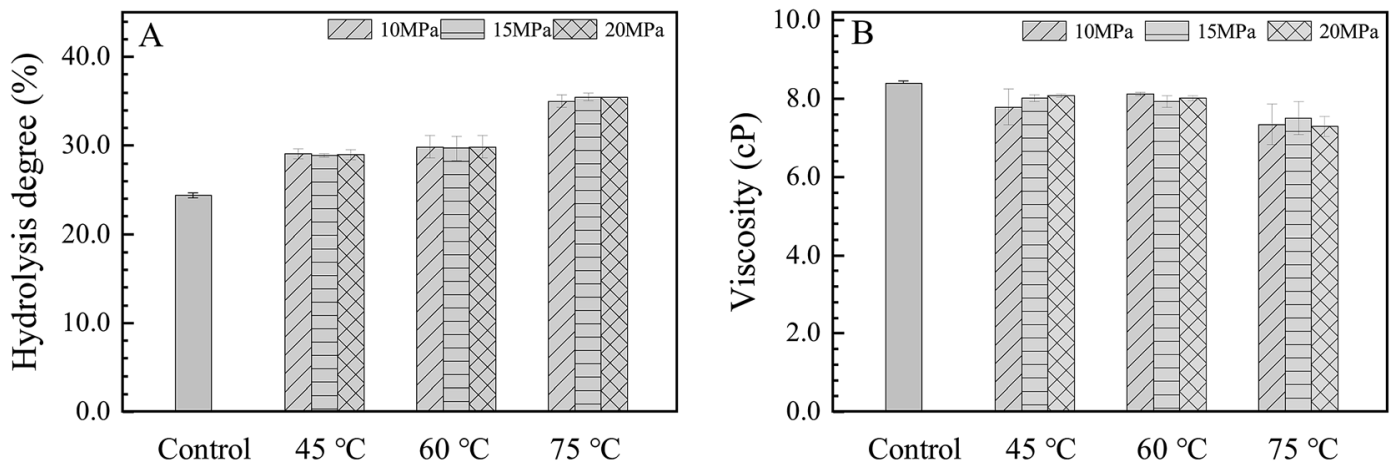

Fig. 2 The HPAM hydrolysis degree and solution viscosity as a function of treatment temperature/pressure.

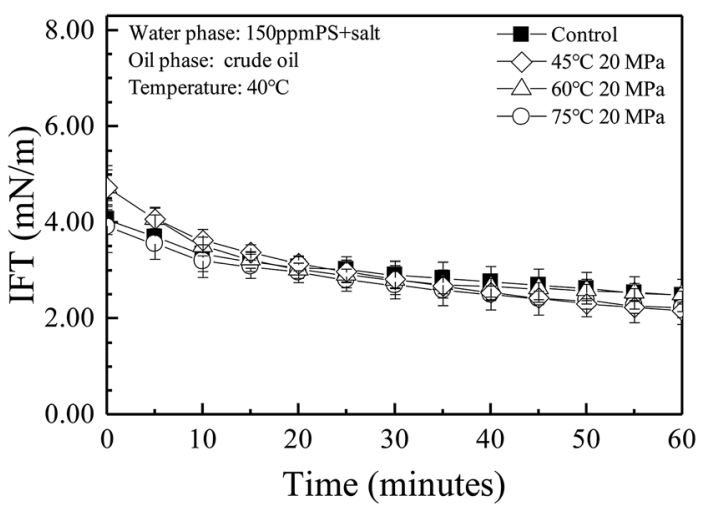

Fig. 3 Comparison of the oil-water interfacial tension before and after temperature/pressure treatment for the PS solutions.

stabilization of emulsions was mainly attributed to its ability of decreasing the oil-water interfacial tension. As shown in Fig. 3, the crude oil-water interfacial tension of the PS solution did not change over the whole temperature range from 45 to $75^{\circ} \mathrm{C}$.

Fig. 4(B) showed the influence of the additional HPAM to the stability of the emulsion containing $500 \mathrm{mg} \mathrm{L}^{-1} \mathrm{PS}$ as the background surfactant. By comparing with Fig. 4(A), the remaining oil content increased from 2886 to $3068 \mathrm{mg} \mathrm{L}^{-1}$ with the addition of $100 \mathrm{mg} \mathrm{L}^{-1}$ control HPAM. So the addition of control HPAM could also enhance the emulsion stability. The emulsion stabilization ability of the polymer was believed to be mainly derived from its ability in increasing the viscosity of the water phase.$^{14}$ However, the remaining oil content decreased to 2264, 2168 and $2032 \mathrm{mg} \mathrm{L}^{-1}$, respectively, when the same concentration of HPAM treated at 45,60 and $75{ }^{\circ} \mathrm{C}$ were added, suggesting that the addition of the treated HPAM destabilized the emulsions. As shown in Fig. 1(B) and 2(A), the HPAM MW decreased by $62 \%$ after being treated at $75^{\circ} \mathrm{C}$ for one week, and the HPAM hydrolysis degree increased as much as $11 \%$. It is possible that the treated HPAM acted as a flocculent rather than a stabilization agent in this case. It is also suggested that the stabilization ability of HPAM is dependent on its molecular weight, hydrolysis degree and concentration. For the treated HPAM, with a lower MW, maybe more than $100 \mathrm{mg} \mathrm{L}^{-1}$ of HPAM would be needed to stabilize the oil/water emulsions. It is known that different oil reservoirs have different temperatures, and the concentrations of PS and HPAM might also be quite different. ${ }^{34-36}$ The residence time of PS and HPAM in the oil reservoir may be longer than six months. ${ }^{35,37}$ Hence, further studies should be done to explore the critical conditions that determine the destabilization or stabilization effects of the back produced flooding reagents on the PW in the EOR processes.
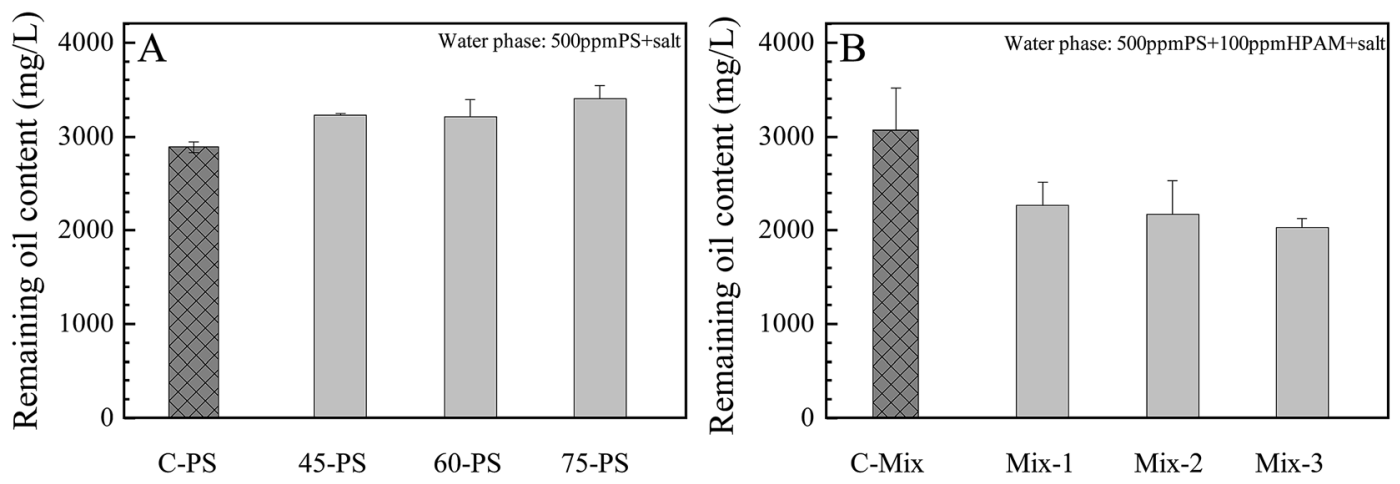

Fig. 4 The impact of the increased treatment temperature on the oil-water emulsion stabilization ability of HPAM/PS. The simulated oil/water emulsions were kept at $45^{\circ} \mathrm{C}$ for $24 \mathrm{~h}$. C-PS, 45-PS, 60-PS and 75-PS represent the simulated oil/water emulsions prepared using control PS and treated PS by 45,60 and $75^{\circ} \mathrm{C}$ with $20 \mathrm{MPa}$, respectively; C-Mix, Mix-1, Mix-2 and Mix-3 represent the simulated oil/water emulsions prepared using $500 \mathrm{mg} \mathrm{L}^{-1} \mathrm{PS}$ in combination with control HPAM and those treated by 45,60 and $75^{\circ} \mathrm{C}$ under $20 \mathrm{MPa}$, respectively. 


\section{Conclusion}

In this study, the fate (property changes) of partially hydrolyzed polyacrylamide (HPAM) and petroleum sulfonate (PS) were investigated under a simulated oil reservoir at different temperature and pressure conditions. The degree of hydrolysis was increased, while the molecular weight $\left(M_{\mathrm{w}}\right)$ of HPAM was decreased as a function of raising the temperature from 45 to $75{ }^{\circ} \mathrm{C}$. The increase in pressure would impede the degradation of the HPAM $M_{\mathrm{w}}$ and did not show obvious changes on the degree of hydrolysis of HPAM. It was noted that temperature and pressure treatment resulted in a decreased viscosity of HPAM solutions, but no perceptible changes occurred for the interfacial tensions of PS on the oil-water interface. The emulsifying capacity of PS was not affected by rising temperature, however, it was decreased to some extent for the treated HPAM. It is possible that the critical conditions for the back produced flooding reagents to stabilize or destabilize the PW would play a key role in the wastewater treatment technology and, therefore, further studies should be conducted.

\section{Conflicts of interest}

The authors declare that there are no conflicts of interest.

\section{Acknowledgements}

The authors thank financial supports from the State Hi-tech Research and Development Project of the Ministry of Science and Technology, People's Republic of China (No. 2012AA063401).

\section{References}

1 S. J. Guerrero, P. Boldarino and J. A. Zurimendi, J. Appl. Polym. Sci., 1985, 30, 955-967.

2 L. H. Zhang, D. Zhang and B. Jiang, Chem. Eng. Technol., 2006, 29, 395-400.

3 M. Pratap and M. S. Gauma, presented in part at the SPE Asia Pacific Oil and Gas Conference and Exhibition, Perth, Australia, 2004/1/1.

4 M. J. Pitts, P. Dowling, K. Wyatt, H. Surkalo and K. C. Adams, presented in part at the SPE/DOE Symposium on Improved Oil Recovery, Tulsa, Oklahoma, USA, 2006/1/1.

5 M. J. Pitts, K. Wyatt and H. Surkalo, presented in part at the SPE/DOE Symposium on Improved Oil Recovery, Tulsa, Oklahoma, 2004/1/1.

6 H. Jiang, Q. Yu and Z. Yi, Pet. Sci. Technol., 2011, 29, 514-521.

7 J. Lu, A. Goudarzi, P. Chen, D. H. Kim, M. Delshad, K. K. Mohanty, K. Sepehrnoori, U. P. Weerasooriya and G. A. Pope, J. Pet. Sci. Eng., 2014, 124, 122-131.

8 L. Xu, G. Xu, T. Liu, Y. Chen and H. Gong, Carbohydr. Polym., 2013, 92, 516-522.

9 L. Xu, M. Dong, H. Gong, M. Sun and Y. Li, Carbohydr. Polym., 2015, 121, 147-154.

10 L. Xu, H. Gong, M. Dong and Y. Li, Carbohydr. Polym., 2015, 132, 620-629.
11 J. R. Hou, Z. C. Liu, S. F. Zhang, X. Yue and J. Z. Yang, J. Pet. Sci. Eng., 2005, 47, 219-235.

12 R. Zolfaghari, A. A. Katbab, J. Nabavizadeh, R. Y. Tabasi and M. H. Nejad, J. Appl. Polym. Sci., 2006, 100, 2096-2103.

13 X. Ge, J. Yang, X. Xu and J. Gao, Pet. Sci. Technol., 2010, 28, 1013-1024.

14 R. S. Al-Maamari, M. Sueyoshi, M. Tasaki, K. Kojima and K. Okamura, Oil Gas Facil., 2014, 3, 89-100.

15 B. Ma, B. Gao and Q. Yue, J. Pet. Sci. Eng., 2013, 110, 27-31. 16 S. Deng, R. Bai, J. P. Chen, G. Yu, Z. Jiang and F. Zhou, Colloids Surf., A, 2002, 211, 275-284.

17 H. Ghojavand, F. Vahabzadeh and A. K. Shahraki, J. Pet. Sci. Eng., 2012, 81, 24-30.

18 F. Zhang, Y. H. She, H. M. Li, X. T. Zhang, F. C. Shu, Z. L. Wang, L. J. Yu and D. J. Hou, Appl. Microbiol. Biotechnol., 2012, 95, 811-821.

19 N. K. Harner, T. L. Richardson, K. A. Thompson, R. J. Best, A. S. Best and J. T. Trevors, J. Ind. Microbiol. Biotechnol., 2011, 38, 1761-1775.

20 M. M. Yakimov, M. M. Amro, M. Bock, K. Boseker, H. L. Fredrickson, D. G. Kessel and K. N. Timmis, J. Pet. Sci. Eng., 1997, 18, 147-160.

21 R. T. Bachmann, A. C. Johnson and R. G. J. Edyvean, Int. Biodeterior. Biodegrad., 2014, 86, 225-237.

22 V. F. Kurenkov, H. G. Hartan and F. I. Lobanov, Russ. J. Appl. Chem., 2002, 75, 1039-1050.

23 B. H. Zimm, J. Chem. Phys., 1948, 16, 1093-1099.

24 B. H. Zimm, J. Chem. Phys., 1948, 16, 1099-1116.

25 J. Wang, H. Huang and X. Huang, J. Appl. Polym. Sci., 2016, 133.

26 J. Klein and A. Westerkamp, J. Polym. Sci., Polym. Chem. Ed., 1981, 19, 707-718.

27 V. F. Kurenkov, P. V. Trofimov, A. V. Kurenkov, K. G. Khartan and F. I. Lobanov, Russ. J. Appl. Chem., 2005, 78, 995-999.

28 H. Anger and G. Berth, Carbohydr. Polym., 1986, 6, 193-202.

29 H. Kheradmand, J. François and V. Plazanet, Polymer, 1988, 29, 860-870.

30 J. Cohen, Z. Priel and Y. Rabin, J. Chem. Phys., 1988, 88, 7111-7116.

31 J. Cohen and Z. Priel, J. Chem. Phys., 1990, 93, 9062-9068.

32 G. Muller, J. P. Laine and J. C. Fenyo, J. Polym. Sci., Polym. Chem. Ed., 1979, 17, 659-672.

33 M. E. Zeynali, A. Rabii and H. Baharvand, Synthesis of partially hydrolyzed polyacrylamide and investigation of solution properties (Viscosity Behaviour), 2004.

34 Y. Zhang, M. Wei, B. Bai, H. Yang and W. Kang, presented in part at the SPE Improved Oil Recovery Conference, Tulsa, Oklahoma, USA, 2016/4/11.

35 H. Groeneveld, R. A. George and J. C. Melrose, SPE-5829-PA, 1977, vol. 29, pp. 561-570.

36 A. G. Putz, B. Bazin and B. M. Pedron, presented in part at the SPE Annual Technical Conference and Exhibition, New Orleans, Louisiana, 1994/1/1.

$37 \mathrm{M}$. Zettlitzer and $\mathrm{H}$. Volz, presented in part at the SPE/DOE Enhanced Oil Recovery Symposium, Tulsa, Oklahoma, 1992/ $1 / 1$. 